Volume 8, No.6, November - December 2019

International Journal of Advanced Trends in Computer Science and Engineering

Available Online at http://www.warse.org/IJATCSE/static/pdf/file/ijatcse51862019.pdf

https://doi.org/10.30534/ijatcse/2019/51862019

\title{
What Features Emerge when Asian Countries are Matched Across Productivity and Social Media Use? : A Basis for Complex Adaptive Analysis
}

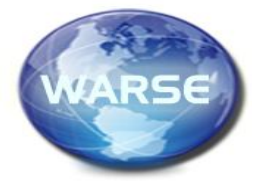

ABSTRACT

Improving content sharing on social media platforms helps firms enhance the efficacy of their marketing campaigns. This paper aimed to determine the economic growth and number of Facebook users from Asian countries, determine the complex adaptive behavior of economies in Asia, and determine the emergent features of the countries in each cluster and with other clusters within Asia. The 49 countries in Asia as the agents show a direct interaction with each other as to their specified traits, which are the economic growth and Facebook users. The emergent feature of the countries with traits namely the economic growth and facebook users show a rapidly fluctuating economic growth for smaller facebook values and, through the amplitudes decrease with increasing facebook users. In the limit, the economic growth figures are no longer impaired by the number of Facebook users.

Key words: Complex adaptive systems, economic growth, emergent features, facebook users

\section{INTRODUCTION}

Complex Adaptive Systems (CAS) are systems that display two primary characteristics: emergent behavior and adaptive behavior. Emergent behavior manifests in a system comprising of large number of components, often considered as agents, engaged in multi-level interactions. Adaptive behavior manifests at the agent-environment boundary when the agent situates itself in an environment [1]. Synergy is defined broadly as the combined (interdependent) effects produced by two or more parts, elements or individuals-is a ubiquitous phenomenon in nature and human societies alike [2].

Improving content sharing on social media platforms helps firms enhance the efficacy of their marketing campaigns [3]. Social network platforms (SNPs) such as Facebook, YouTube, LinkedIn, and Instagram are now an integral part of customers' lives. These platforms, as online hosts, facilitate the development and maintenance of user-profiles and encourage inter-user communication among the consumers [4].

The social connectivity will determine the sociological formation of relationships among people in the country and with the other countries. The economic connectivity unlocks new opportunities through connecting people and businesses, lowering barriers to marketing, and stimulating innovation. Therefore, this paper aimed to identify what features emerge when Asian countries are matched across productivity and social media use as a basis for complex adaptive analysis. Specifically, this paper sought to determine the economic growth and the number of Facebook users from Asian countries, determine the complex adaptive behavior of economies in Asia and determine the emergent features of the countries in each cluster and with other clusters within Asia.

\section{METHODOLOGY}

The researchers gathered data set on Facebook users as well as the Gross Domestic Product (GDP), which also signifies the economic growth of the 49 countries. These data were taken from the World Bank Open Data, a website for free and open access to global development data. The data obtained for economic growth is in percentage form while the data for Facebook users is the actual count. These data were then renormalized through excel for it to be fitting in the study since synergy only requires 0 to 1 values. By definition, renormalization is the procedure in quantum field theory by which divergent parts of a calculation, leading to nonsensical infinite results, are absorbed by redefinition into a few measurable quantities to yielding finite answers [5].

Moreover, after the renormalization process, it has been loaded as input to the Calculator Synergy. It is an application developed by Northwestern Mindanao State College of Science and Technology (NMSC) of Tangub City, that is capable of managing the synergy calculation. Synergy is the benefit that results when two or more agents work together to achieve something either one couldn't have achieved on its own. It's the concept of the whole being greater than the sum of its parts. This process was applied in the study in getting the number of positive and negative synergies among 49 countries. The summary of positive synergy was used to cluster the countries. The scatterplot is used in the study to determine the emergent features of the countries.

\subsection{Conceptual Framework}

Figure 1 shows the conceptual framework of the study where countries are considered as agents. Countries A and B show a direct interaction with each other as to their specified traits, which are the economic growth and Facebook users. As they continue to interact, the two countries shared their social information as well as engaged in joint economic pursuits. Each country has the attributes or characteristics 
namely the Economic Growth and Facebook Users. Given the traits from each country, they are clustered or grouped based on their similarities. The similarity of countries A and $\mathrm{B}$ are measured through nonlinear correlation. The nonlinear correlation is called synergy. To calculate synergy, the following equation is utilized:

$$
\operatorname{Synergy}(\mathrm{A}, \mathrm{B})=\mathrm{EG}(\mathrm{A}) * \mathrm{EG}(\mathrm{B})+\mathrm{FU}(\mathrm{A}) * \mathrm{FU}(\mathrm{B})
$$

The emergent features of each cluster are described based on the similarities in Economic Growth and Facebook Users. The overall result is also a determining factor to describe what features emerge when Asian countries are matched across productivity, and social media use.

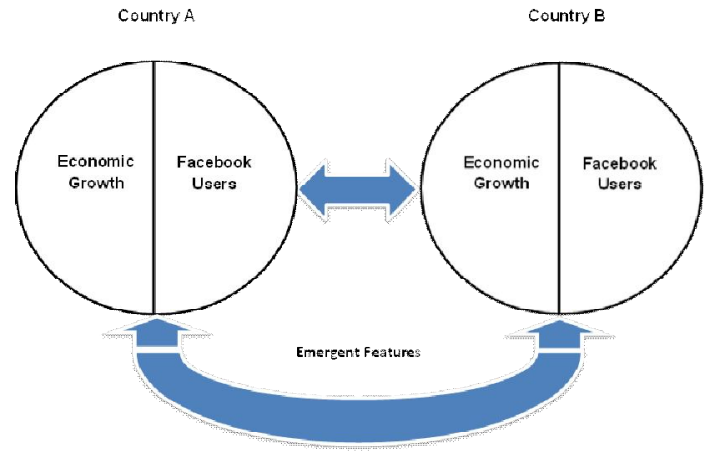

Figure 1: Conceptual Framework

\section{RESULTS AND DISCUSSION}

The following table and graphs present the economic growth and Facebook users in Asian countries for the year 2018 with its renormalized data set.

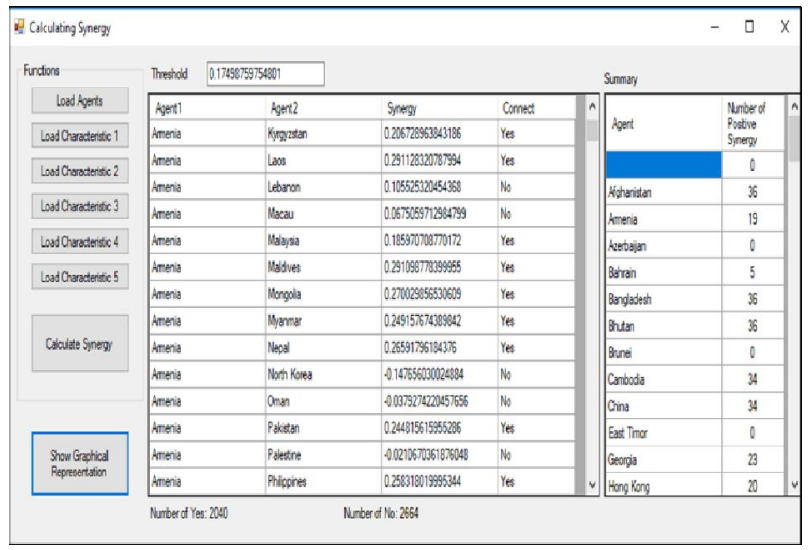

Figure 2: Synergy calculation

Figure 2 shows the process of calculating the synergy of the study where the countries in Asia were loaded as the agents; while EG and FU were loaded as both positive synergies.

Table 1 presents the summary of the result for synergy calculation. It also shows the relationship between countries; on how they have reacted to the synergy among them. As shown, India has the highest number of positive synergy. It means that being the highest Facebook users, they also have the highest positive synergy with other countries. This positive synergy determines that its socio-economic connectivity through Facebook has also led to its economic growth. This was supported by the report released by Deloitte (a consultancy firm), where it states that "Facebook's impact on India has an estimated $\$ 4$ billion and 335,000 jobs have been benefited. With over 112 million users, India is the second-largest market for Facebook". Furthermore, the countries which have zero (0) positive synergy like Azerbaijan, East Timor, Iraq, Oman, Palestine, and United Arab Emirates also got a lesser rate of economic growth.

Table 1: Summary of synergy calculation

\begin{tabular}{|c|c|}
\hline Agents & Positive Synergy \\
\hline Afghanistan & 36 \\
\hline Armenia & 19 \\
\hline Azerbaijan & 0 \\
\hline Bahrain & 5 \\
\hline Bangladesh & 36 \\
\hline Bhutan & 36 \\
\hline Brunei & 0 \\
\hline Cambodia & 34 \\
\hline China & 34 \\
\hline East Timor & 0 \\
\hline Georgia & 23 \\
\hline Hong Kong & 20 \\
\hline India & 37 \\
\hline Indonesia & 32 \\
\hline Iran & 15 \\
\hline Iraq & 0 \\
\hline Israel & 21 \\
\hline Japan & 1 \\
\hline Jordan & 15 \\
\hline Kazakhstan & 25 \\
\hline Kuwait & 14 \\
\hline Kyrgyzstan & 28 \\
\hline Laos & 34 \\
\hline Lebanon & 18 \\
\hline Macau & 5 \\
\hline Malaysia & 27 \\
\hline Maldives & 34 \\
\hline Mongolia & 34 \\
\hline Myanmar & 33 \\
\hline Nepal & 34 \\
\hline North Korea & 1 \\
\hline Oman & 0 \\
\hline Pakistan & 32 \\
\hline Palestine & 0 \\
\hline Philippines & 34 \\
\hline Qatar & 17 \\
\hline Saudi Arabia & 19 \\
\hline Singapore & 17 \\
\hline South Korea & 22 \\
\hline Sri Lanka & 20 \\
\hline Syria & 1 \\
\hline Taiwan & 13 \\
\hline Tajikistan & 36 \\
\hline Thailand & 22 \\
\hline Turkmenistan & 32 \\
\hline United Arab Emirates & 0 \\
\hline Uzbekistan & 30 \\
\hline
\end{tabular}




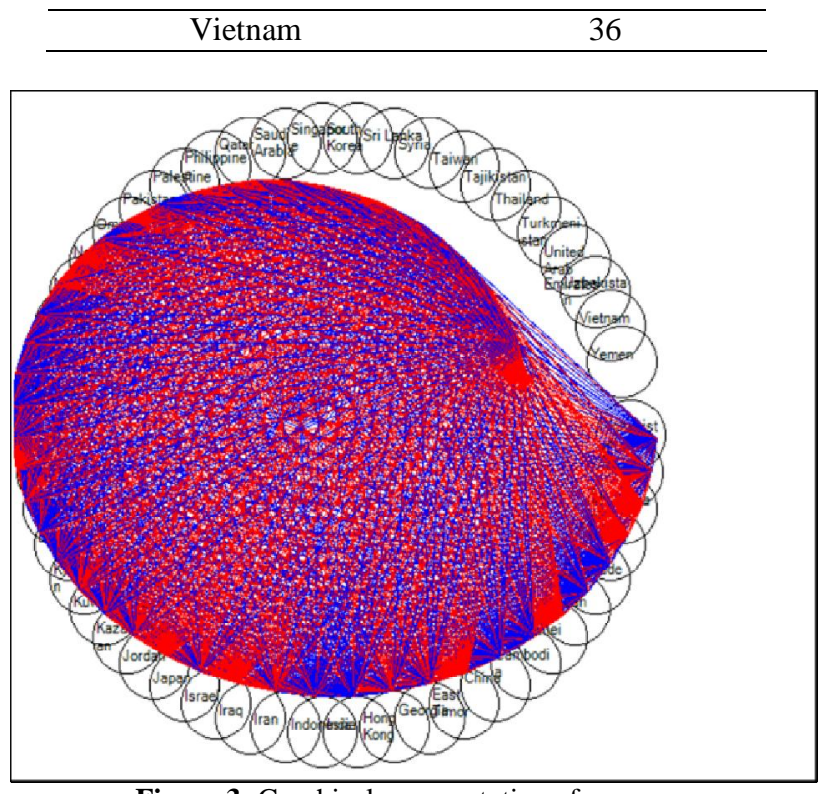

Figure 3: Graphical representation of synergy

Figure 3 shows the graphical representation of the study after the summary of synergy was obtained from the process of its computation. The blue signifies the positive synergy, and red signifies the negative connections.

Table 2: Clustering of countries

\begin{tabular}{lll}
\hline & Clustering of Countries \\
\hline 0-5 positive synergy & 6-25 positive synergy & 26-up positive synergy \\
Cluster 1 & Cluster 2 & Cluster 3 \\
Bahrain & Armenia & Afghanistan \\
Japan & Hong Kong & Bangladesh \\
Macau & Iran & Bhutan \\
North Korea & Israel & India \\
Syria & Jordan & Indonesia \\
Azerbaijan & Kuwait & Kyrgyzstan \\
Brunei & Lebanon & Laos \\
East Timor & Qatar & Malaysia \\
Iraq & Saudi Arabia & Maldives \\
Oman & Sri Lanka & Mongolia \\
Palestine & Taiwan & Myanmar \\
UAE & Thailand & Nepal \\
& Georgia & Pakistan \\
& Israel & Philippines \\
& Kazakhstan & Tajikistan \\
& Singapore & Turkmenistan \\
& & Uzbekistan \\
& & Vietnam \\
& & Cambodia \\
\hline
\end{tabular}

Three clusters (3) were classified after the calculation of positive synergy among the 49 countries in Asia. The countries that obtained $0-5$ positive synergies are grouped in Cluster 1; Cluster 2 has countries that obtained $6-25$ positive synergy while countries with 25 and above positive synergy are grouped in Cluster 3 as shown in Table 2. These countries have been clustered based on their number of synergies with other countries. As shown in the table, Cluster 3 has the highest number of countries with more interactions with each other. Cluster 1, in contrary, has the lowest number of interactions

\subsection{Emergent Features}

The figures below illustrate the emergent features based on the similarities in EG and FU attributes in each cluster.

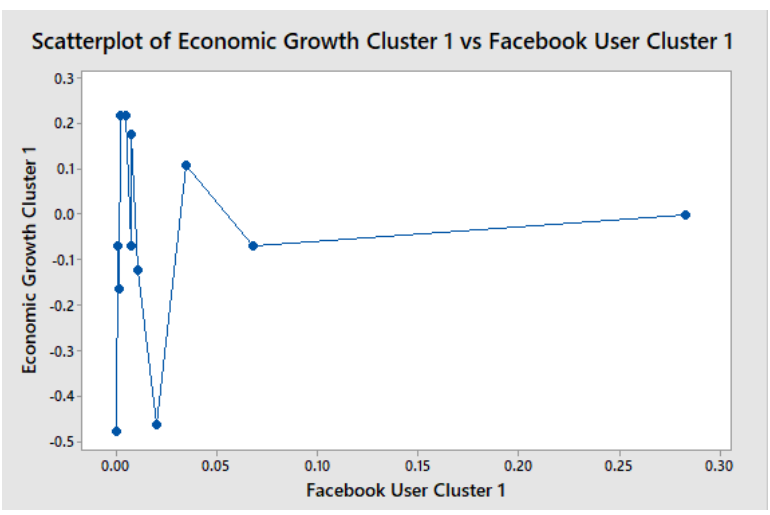

Figure 4: Cluster 1 Scatterplot of EG and FU

As shown in Figure 4, the emerging feature is the limit of influence of facebook users on the economic growth of countries in this cluster. This is contrary to the study of [6] that Facebook is becoming increasingly crucial for the socio-economic development of countries across the globe as stakeholders engage in online social interaction and expand their reach for new products, services, and markets to open up new revenue streams. In Japan, Twitter is used by a lot of people even when compared to other countries. The main reason is that Twitter was beneficial during the Great East Japan Earthquake of 2011. Twitter holds the top crown for social media in Japan and is not slowing down at all [7].

Moreover, Facebook users are fewer than two million, or less than 2 percent of the country's online population [8]. According to [9], Facebook has failed to dominate Japan as it has in the United States and Europe. Japanese prefer to use Twitter, which makes \$2.36 per Japanese user, compared with $\$ 5.97$ per user in the United States, according to data from the fourth quarter of 2017. It is almost twice the \$1.24 in revenue per non-U.S. user overall.

Another country included in cluster 1 is North Korea, in which internet access is strictly limited. As stated by [10], it is not known how many people have direct access to the global internet, but estimates generally place the figure at a small fraction of one percent of the population of about 25 million. North Korea's ruling class has, in recent months, abandoned Western social media sites such as Facebook (FB.O), Instagram, and Alphabet's Google (GOOGL.O) and dramatically increased its use of tools that cloak internet activity, according to cybersecurity research [11].

Figure 6 shows the concave effect of the countries in cluster 2. While the number of Facebook users is small, its impact on the Economic Growth remains volatile. At a certain point, economic growth rises as the number of facebook users increases. Economic Growth increases again beyond the point 0.05 , and it became counterproductive optimal, e.g.: $0.05-5 \%$ of population.

Facebook, being the second most visited website in the world and no.1 in Sri Lanka, could be identified as a special kind of addiction today where an average user browses Facebook at least for 30 minutes a day from computers or smart devices and gets exposed to diverse content of Facebook as a habit [12]. Sri Lanka uses the internet to shop and to research new goods or services. Out of all the internet users, about $86 \%$ of them will find their way to Facebook. 
The same goes to Georgia, where its new statistics about Facebook use revealed that there are twice more people (757,460 to be exact) who use the platform than at the beginning of 2011, according to Socialbakers, provider of social media trends. According to the same statistics, Georgia ranks as the \#1 country in the region in terms of the use of Facebook, even surpassing Azerbaijan, which has a twice as large population and the number of people with access to the internet is roughly three times more than in Georgia.

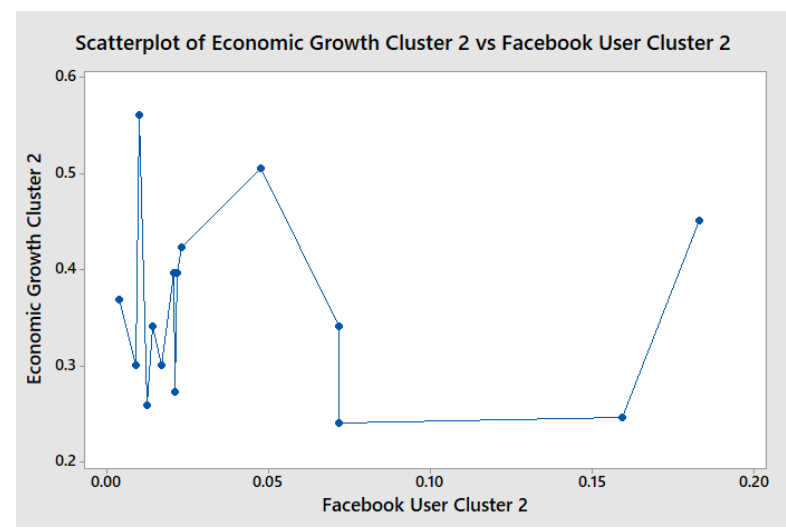

Figure 5: Cluster 2 Scatterplot of EG and FU

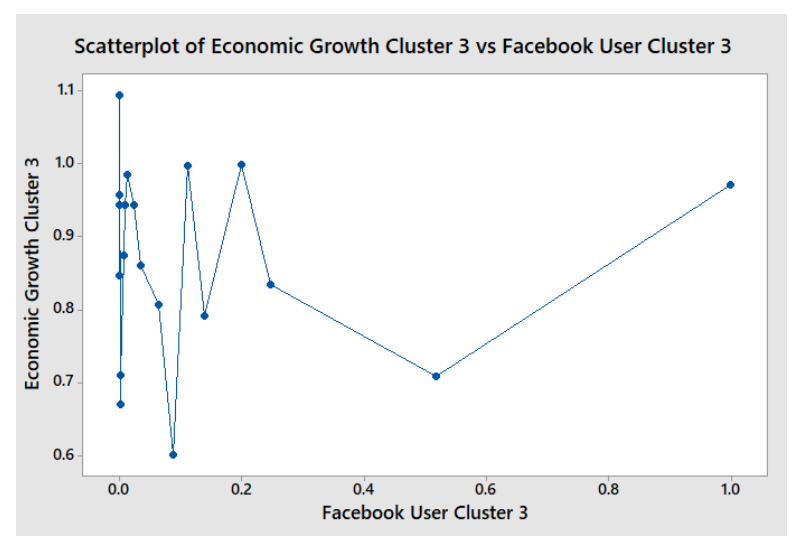

Figure 6: Cluster 3 Scatterplot of EG and FU

Figure 7 shows the random effect of countries in cluster 3 . It revealed that Facebook users have no impact on economic growth of the country. Since 1980, China and India have achieved remarkable rates of economic growth and poverty reduction. The emergence of China and India, as major force in the global economy, has been one of the most significant economic developments of the past quarter-century [13]. China has the largest number of internet users of any country in the world, but it also has strict censorship, with digital surveillance and a ban on online anonymity in which access to Facebook, Twitter, Instagram, and Snapchat is restricted [14]. Chinese government's decision to block outside Internet sites has also helped foster the growth of home-grown services such as Tencent and Sina Weibo. Social media networks such as Facebook can connect with a community or a group but cannot buy anything unlike WeChat, in which the guest of the site can purchase anything available on the platform. As one venture capitalist puts it,
WeChat is about 1.5 years ahead of Facebook in terms of social commerce [15].

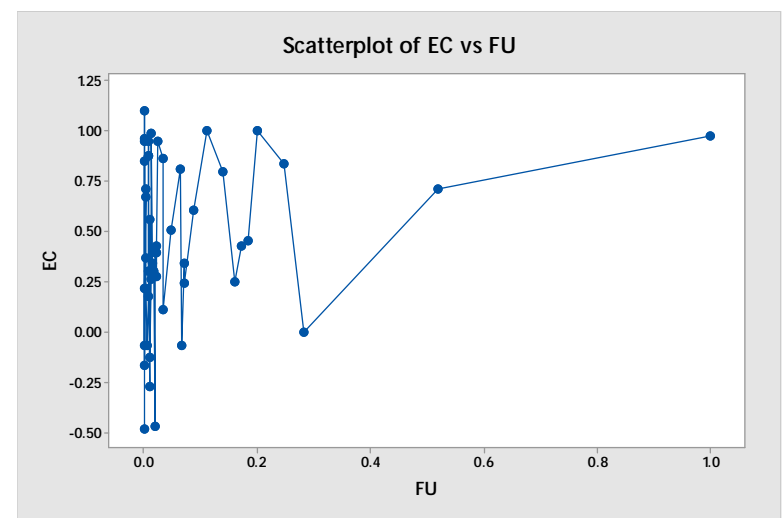

Figure 7: Scatterplot of EG and FU in Asia

Figure 8 shows the random effect of Facebook Users on the Economic Growth of the 49 Countries in Asia. There is certain point in which Facebook users are higher; however, economic growth remains volatile. Like in the country of Japan, which prefers to use other social platforms for information security purposes. Japan's government told U.S. technology firm Facebook Inc. (FB.O) to better protect its users' data following lapses affecting tens of millions of people globally [16]. In addition, the Chinese government's decision to block outside Internet sites has also helped foster the growth of homegrown services such as Tencent and Sina Weibo. For example, since 2010, when Google announced that it would stop censoring search results, the Chinese government has blocked access to Google, disabling the whole range of Google services. As one example, Google Maps lost its dominant market share directly to the homegrown Baidu Maps.

\section{CONCLUSION AND RECOMMENDATION}

The emergent feature of the countries with traits, namely Economic Growth and Facebook Users, shows a rapidly fluctuating economic growth for smaller Facebook values and, thru, the amplitudes decrease with increasing Facebook Users. In the limit, the Economic Growth figures are no longer impaired by the number of Facebook Users.

It is recommended that the use of data mining techniques and algorithms [17]-[25] be observed for further knowledge extraction.

\section{REFERENCES}

[1] S. Mittal, S. Diallo, and A. Tolk, Emergent Behavior in Complex Systems Engineering: A Modeling and Simulation Approach. 2018. https://doi.org/10.1002/9781119378952

[2] P. Corning, "The Synergism Hypothesis: On the Concept of Synergy and its Role in the Evolution of Complex Systems," J. Soc. Evol. Syst., vol. 21, no. 2, 1998. https://doi.org/10.1016/S1061-7361(00)80003-X

[3] J. Peng, A. Agarwal, K. Hosanagar, and R. Iyengar, "Network Overlap and Content Sharing on Social 
Media Platforms," J. Mark. Res., vol. 55, no. 4, 2018. https://doi.org/10.1509/jmr.14.0643

[4] A. Parvatiyar and R. Sisodia, Handbook of Advances in Marketing in an Era of Disruptions Essays in Honour of Jagdish N. Sheth. 2019.

[5] S. S. Schweber, "Changing Conceptualization of Renormalization Theory," in Brown L.M. (eds) Renormalization, New York, NY: Springer, 1993. https://doi.org/10.1007/978-1-4612-2720-5_5

[6] E. J. Y. Liew, S. Vaithilingam, and M. Nair, "Facebook and socio-economic benefits in the developing world," Behaviour and Information Technology, 2014. .

[7] C. Neely, "Japan's Top Social Media Networks for 2018," 2018. [Online]. Available: https://www.humblebunny.com/japans-top-social-m edia-networks-2018/.

[8] H. Tabuchi, "Facebook Wins Relatively Few Friends in Japan," The New York Times, 2011. [Online]. Available:

https://www.nytimes.com/2011/01/10/technolo gy/10facebook.html\%0AThe.

[9] S. Nussey and D. Ingram, "In Japan, Twitter sees a surge of users - and revenue," Reuters, 2018. [Online]. Available: https://www.reuters.com/article/us-twitter-japan/in-j apan-twitter-sees-a-surge-of-users-and-revenue-idU SKCN1GC17T.

[10] E. Groll, "North Korean Internet Users Shun Facebook and Google for Chinese Alternatives," Foreign Policy, 2018. [Online]. Available: https://foreignpolicy.com/2018/04/25/north-korean-i nternet-users-shun-facebook-and-google-forchinese-alternatives/.

[11] D. Volz, "North Korea's elite quitting Facebook, concealing internet activity: researcher," Reuters, 2018. [Online]. Available: https://www.reuters.com/article/us-usa-cyber-northk orea/north-koreas-elite-quitting-facebookconcealing-internet-activity-researcher-idUSKBN1 HW1XC.

[12] T. Rathnayake and D. Rathnayake, "Facebook Usage of Sri Lankan Consumers: Consumption Perspective of Social Media," Arts Soc. Sci. J., vol. 9, no. 4, 2018. https://doi.org/10.4172/2151-6200.1000366

[13] B. Bosworth and Su. M. Collins, "Accounting for Growth: Comparing China and India," J. Econ. Perspect., vol. 22, no. 1, pp. 45-66, 2008.

https://doi.org/10.1257/jep.22.1.45

[14] A. Gray and R. Hutt, "This Chinese Giant Is Now Worth More Than Facebook," World Economic Forum, 2017. [Online]. Available: http://fortune.com/2017/11/21/tencent-market-capita lization-500-billion-facebook/.

[15] Z. Soo, "Forget the glamour, it's a tough life out there: one venture capitalist's hard truths on running start-ups and doing business in China," South China Morning Post, 2016. [Online]. Available: https://www.scmp.com/news/china/money-wealth/ar ticle/1907076/forget-glamour-its-tough-life-outthere-one-venture\%0ASouth.

[16] M. Yamazaki, S. Nussey, and C. Cushing, "Japan tells Facebook to improve data protection," Reuters,
$2018 . \quad$ [Online]. Available: https://www.reuters.com/article/us-facebook-privacy -japan/japan-tells-facebook-to-improve-data-protecti on-idUSKCN1MW0AG.

[17] A. J. P. Delima and M. T. Q. Lumintac, “Application of Time Series Analysis for Philippines ' Inflation Prediction," Int. J. Recent Technol. Eng., vol. 8, no. 1, pp. 1761-1765, 2019.

[18] A. J. P. Delima, "Predicting Scholarship Grants Using Data Mining Techniques," Int. J. Mach. Learn. Comput., vol. 9, no. 4, pp. 513-519, 2019. https://doi.org/10.18178/ijmlc.2019.9.4.834

[19] U. O. Cagas, A. J. P. Delima, and T. L. Toledo, "PreFIC: Predictability of Faculty Instructional Performance through Hybrid Prediction Model," Int. J. Innov. Technol. Explor. Eng., vol. 8, no. 7, pp. 22-25, 2019.

[20] A. J. P. Delima, “Applying Data Mining Techniques in Predicting Index and non-Index Crimes," Int. J. Mach. Learn. Comput., vol. 9, no. 4, pp. 533-538, 2019.

https://doi.org/10.18178/ijmlc.2019.9.4.837

[21] A. J. P. Delima, “An Experimental Comparison of Hybrid Modified Genetic Algorithm-based Prediction Models," Int. J. Recent Technol. Eng., vol. 8, no. 1, pp. 1756-1760, 2019.

[22] A. J. P. Delima and V. C. Francisco, "Rank-based variable minimization using clustering algorithm," Int. J. Mach. Learn. Comput., vol. 9, no. 5, pp. 575-580, 2019. https://doi.org/10.18178/ijmlc.2019.9.5.842

[23] A. J. P. Delima, "Application of Time Series Analysis in Projecting Philippines , Electric Consumption," Int. J. Mach. Learn. Comput., vol. 9, no. 5, pp. 694-699, 2019. https://doi.org/10.18178/ijmlc.2019.9.5.860

[24] A. J. P. Delima, A. M. Sison, and R. P. Medina, “A Modified Genetic Algorithm with a New Crossover Mating Scheme," Indones. J. Electr. Eng. Informatics, vol. 7, no. 2, pp. 165-181, 2019.

[25] A. J. P. Delima, A. M. Sison, and R. P. Medina, "Variable Reduction-based Prediction through Modified Genetic Algorithm," Int. J. Adv. Comput. Sci. Appl., vol. 10, no. 5, pp. 356-363, 2019. https://doi.org/10.14569/IJACSA.2019.0100544 